Portland State University

PDXScholar

\title{
The Incorporation of Fathering Interventions into Batterer Intervention Programs
}

Caitlyn Martin

Portland State University

Follow this and additional works at: https://pdxscholar.library.pdx.edu/honorstheses

\section{Let us know how access to this document benefits you.}

\section{Recommended Citation}

Martin, Caitlyn, "The Incorporation of Fathering Interventions into Batterer Intervention Programs" (2018).

University Honors Theses. Paper 581.

https://doi.org/10.15760/honors.590

This Thesis is brought to you for free and open access. It has been accepted for inclusion in University Honors Theses by an authorized administrator of PDXScholar. Please contact us if we can make this document more accessible: pdxscholar@pdx.edu. 
The Incorporation of Fathering Interventions into Batterer Intervention Programs

by

\section{Caitlyn Martin}

An undergraduate honors thesis submitted in partial fulfillment of the

requirements for the degree of

Bachelor of Science

in

University Honors

and

Criminology \& Criminal Justice

Thesis Adviser

Ericka Kimball

Portland State University

2018 
FATHERING INTERVENTIONS

\begin{abstract}
This paper seeks to answer the question: How are fathering interventions incorporated in batterer intervention programs. A content analysis was conducted on two father focused batterer intervention programs called Caring Dads: Helping Fathers Value their Children and Addressing Fatherhood with Men Who Batter: A Curriculum for Working with Abusive Men as Fathers in a Batterers Intervention Program. These programs were examined and coded for the teaching strategies, teaching topics, visuals, objectives, and structures that each program used. Four common themes (Curriculum Focus, Program Fidelity, Teaching Strategies, Teaching Topics) were found in both programs and compared and contrasted. Exploring these themes indicated that each program's emphasis on program fidelity influences how accurately these programs could be tested for efficacy and evaluated. Another conclusion that was also drawn is that the curriculum focus, teaching strategies, and teaching topics that are employed in each program greatly influence the types of conflicts and battering that the programs will be most effective at preventing and solving.
\end{abstract}




\section{FATHERING INTERVENTIONS}

\section{Introduction}

Domestic violence is a public health issue that affects millions of families throughout the entire globe. Because there are different types of domestic violence, there are many programs that address the actions of men and women who have perpetrated various forms of domestic violence toward their significant other, family members, and/or children. These programs and interventions focus on trying to educate the men that have perpetrated domestic violence about what qualifies as domestic violence, and the different types of conflict management skills these people might use as an alternative to violent and abusive methods. This paper seeks to examine how fathering interventions are integrated into batterer intervention programs. The types of batterer intervention programs that will be examined in this paper are the programs designed to rehabilitate men who have been caught perpetrating different forms of domestic violence. While the two programs examined will accept men with any type of history of domestic violence (except sexual assault), they guide their program with interventions designed to target perpetrators of intimate partner violence and child maltreatment. Domestic violence in its vaguest definition is violence between people living in a household. The Oregon Department of Human Services website defines domestic violence in many different ways but all of these definitions require actions by the batterer that, "include forms of physical injury/abuse, sexual abuse or assault, intimidation, verbal abuse and emotional abuse or threats of such" toward the victim of their abuse. This includes abuse toward an intimate partner, a family member, and/or a child in the household.

Most commonly, when a domestic violence incident is responded to, it is an Intimate Partner Violence (IPV) situation. An IPV situation can contain any of the elements described in the Oregon DHS definition that occur between intimate partners or between parents of a child. Research has estimated $25 \%$ of intimate relationships have involved some sort of domestic violence incident (McHugh \& Frieze 2006). These types of situations can be perpetrated by either male or females and can be directed to people of both genders. A metaanalysis of studies that has researched the various motivations behind intimate partner violence has found that the primary motivations of IPV are power and control, self-defense, expression of negative behavior, and retaliation. While the element of self-defense is almost wholly the motivation of women, no distinct 


\section{FATHERING INTERVENTIONS}

differences of motivations of violence occur between the two genders (Langhinrichsen-Rohling 2012). These motivational elements of violence are some of the main categories that batterer intervention programs try to address in an attempt to reduce future violence.

Another area of domestic violence that will be focused on in this paper is child maltreatment (CM), which contains all of the elements of the definition and/or the neglect of a child. In the past 20 years, studies has shown exposure to IPV that occurs in households can have a negative effect on the child (Edleson 1999; Wolfe et al. 2003; Rothman et al. 2007). This can include actions in which the child experiences one of their parents being physically abused, listening to arguments and abuse occurring between other members of the household, experiencing a parent be insulted and degraded, as well as many other examples. A child that has been exposed to domestic violence can be influenced to have a skewed or negative impression of the battered parent and can undermine the relationship the child has with that parent (Scaia et al. 2010).

While these two forms of domestic violence very often occur in the same household and are typically perpetrated by the same person (Edleson 1999), the criminal justice and public service response to CM and IPV typically operate in two drastically different ways that are based on different ideals and beliefs. Physical displays of IPV are commonly responded to by the police and can often result in a domestic violence charge and/or arrest. Child maltreatment has almost always been addressed by Child Protection Services and not through the same criminal justice circles that IPV is addressed in (Scott \& Crooks 2007, Labarre et al. 2016). While the response to child maltreatment almost always has focused on the mothers and ignored the influence and the need of the fathers, in the past 20 years new research has recommended the father deserves to have the same resources as the mothers in addressing and trying to prevent child maltreatment (Zanoni 2014, Scott 2007).

\section{Literature Review}

More than three million children experience domestic violence occurring in their household each year, an event that can result in a range of negative behaviors and relationships for the child involved (Kimball 2015, Rothman et al. 2007, Edleson 1999). A line of research started in 1990 has come to the conclusion $30 \%$ to $70 \%$ of children that are abused are victims of the same person that batters their 
FATHERING INTERVENTIONS

mother (Rothman et al. 2007). Children can be exposed to domestic violence in a number of ways that can negatively affect them without being the intended victim of the abuse including watching domestic violence occur, hearing it occur, and watching how it effects each parent after the event (Edleson 1999). Experiencing these events can also result in the normalization of the use of violence in the household and possibly instill a lack of respect for women because they can be more easily victimized (Edleson 1999, Wolfe et al. 2003, Scaia et al. 2010, Pennell 2013). These types of perceptions regarding violence and relationships can lead to a cycle of intergenerational violence. While exposure to domestic violence can have an immediate effect upon the emotions and behaviors of the child, it can also have far-reaching effects on the child's family dynamics when they are older and have children and relationships of their own.

Of the many domestic violence cases that are perpetrated by men, many involve elements of both IPV and CM. The average number of domestic violence incidents reported to the police in the United States is $1,314,593$ for a given year, with $67.6 \%$ of these cases involving elements of IPV (Reaves 2017). While CM incidents might have occurred in these settings, the cases surrounding child maltreatment are typically forwarded to Child Protective Services to be addressed. Men's use of violence can involve incidents intended to hurt the mother without the men realizing it can have a negative impact on their children as well (Scott \& Crooks 2007, Pennel et al. 2013). These examples of IPV can be used to control, coerce, degrade, and manipulate the mother. Men can employ various methods such as physical abuse, criticizing and degrading the mother, restricting financial access, and many others as a way to deal with their frustration while controlling their family members. In some cases, abuse can occur with the men's full knowledge that their abuse can have a negative impact while in others the men may not realize their behavior can negatively affect their loved ones.

Two of the predominant theories to explain why men batter are the feminist theory and the cognitive-behavioral theory. The feminist theory is framed around the ideal that men batter because they do not have respect for the women in their lives, or even women in general. These batterers believe they are entitled to be in control of the women in their lives, and the mother of their children should listen to 
FATHERING INTERVENTIONS

them and treat them with full respect. Under this theory, the men's ideals justify their belief that they have a right to use abusive methods to exert dominance over the women and children in their lives (Babcock, Green, \& Rodie 2002; Scott 2004; Saunders 2008). Another common explanation as to why men batter is they have not learned non-abusive skills to cope with frustrations and resolve conflicts (Scott 2004). This cognitive-behavioral theory says men default to using violent and abusive methods when they have not learned a better way to respond to conflicts (Scott 2004; Scott \& Crooks 2007; Saunders 2008; Labarre et al. 2016). This theory is extremely applicable to explain child maltreatment because it supports the idea men would use abusive methods to cope with children who were being uncooperative or acting out. Both of these theories are the base of all of the objectives, structure, and teaching strategies in almost all batterer intervention programs that have been implemented (Scaia et al. 2010, Scott et al. 2013).

Child maltreatment is commonly perpetrated by the same men that batter their intimate partners (Edleson 1999). CM can also incorporate the aspect of child neglect which means ignoring the needs of the child. This can involve refusing to feed or house a child, refusing to get a child medical care when they need it, or just simply ignoring the child (Wissow 1995). Batterers can resort to using child maltreatment because they do not know any healthy ways to respond to conflict with their children. They do not have knowledge of children's development stages, so they have expectations that are too high for the developmental level of the child and their response to this dilemma is to mistreat their children to make the children do what they want them to do (Scaia et al. 2010, Scott et al. 2013). Instead of controlling frustration and anger at the child, the battering partner can use a variety of abusive methods that come more as instinct than the self-control required to respond to familial conflicts in a calm and healthy way.

The high level of overlap between the men who perpetrate domestic violence and child maltreatment suggests that there should be more supports and responses for the men who have picked up the fathering role in a home who perpetrate both types of abuse (Labarre et al. 2016, Pennell 2013, Scott 2007, Rothman et al. 2007). Research has found that while fathers usually spend less time with their children, they still perpetrate $47.7 \%$ of child maltreatment (Pennel 2007). Because men have been found 


\section{FATHERING INTERVENTIONS}

to be the perpetrators in just as many child maltreatment cases as women, and often in a more physically violent way, the past research suggests men are just as culpable as women for child maltreatment and neglect. There have been many recommendations that fathering programs should be incorporated into batterer intervention programs to address father's violence toward their intimate partners as well as their children (Edleson 1999, Scott 2004). These recommendations are based on the premise that these programs are useful to combat child maltreatment while also combatting intimate partner violence. Employing different teaching strategies, these father-focused batterer intervention programs focus on different types of parenting skills and conflict management techniques to teach the men how to respond to conflict that occurs with the women and children in their lives.

In the past 20 years, there have been various curriculums established that use different aspects of fathering programs and different aspects of batterer intervention programs. These programs attempt to apply the ideals that batterer intervention programs are based on and apply them to reducing violence toward children as well as women (Caring Dads, Strong Fathers, Addressing Fatherhood). Because these types of programs were recently piloted, there is little evaluation literature available to determine how effective they are (Labarre et al. 2016, Scott \& Crooks 2007, Scott \& Lishak 2012). All father-focused batterer intervention programs have two primary objectives they seek throughout the course of the program: increasing accountability in violent fathers for the violent actions they commit and teaching positive fathering techniques in an effort to improve the father-child relationship (Labarre et al. 2016). These programs are conducted with the primary goal of teaching the men why battering is wrong and how not to batter while still ensuring the safety of the women and the children that are in the men's lives.

\section{Father-Focused Batterer Intervention Programs}

The first of two program curriculums that will be examined in this paper is the Caring Dads: Helping Fathers Value their Children program curriculum which is one of the first batterer intervention programs that integrated fathering information and skills. It was first established in 2001 by the authors and creators Katreena Scott, Tim Kelly, Claire Crooks, and Karen Francis and it has been implemented 
FATHERING INTERVENTIONS

primarily in Canada and a few select sites in the United Kingdom. This program curriculum was designed in an effort to create a program that would attempt to hold men accountable for the abuse they inflicted on their intimate partners and children and prevent them from battering the people in their lives in the future. It targets men that have had a history of abuse and currently have contact with their children. This program manual lays out the objectives and goals of the Caring Dads program and provides an in-depth and precise layout for the way each of the sessions, and the exercises within the sessions, should be conducted to effectively teach the goals of each session with the expectation that the program administrators will be instructed in the way to properly teach the curriculum. Since its publication the authors of the program have conducted evaluations, interviews, and an efficacy study of some Caring Dads groups in an effort to improve the later editions of the program curriculum and address the problems found in the study (Scott \& Crooks 2007, Scott \& Lishak 2012).

The second program curriculum that will be examined in this paper is Addressing Fatherhood with Men Who Batter: A Curriculum for Working with Abusive Men as Fathers in a Batterers Intervention Program (BIP). This program manual was designed and written by Melissa Scaia, Laura Connelly, and John Downing and has been implemented in Minnesota and a small selection of other US towns and cities. It is a general program design that provides four distinct themes with supporting core messages, stories, context, and exercises to use when conducting a BIP based on the curriculum. It was designed to be an addition to existing batterer intervention programs that are based on the Duluth model and ideals. This program seeks to offer the option of parenting information and skills to the men who have been found guilty of abusing the women in their lives, but it does not require its participants to have children at the time they take the class because the authors acknowledge the fact it is likely that at some point in the participant's lives they will have children or be a parenting figure for a child in their lives. While this program has published a 2 nd edition, there have not been any evaluation or efficacy literature focused solely on the Addressing Fatherhood program, making it difficult to determine precisely how effective the program is in reducing domestic violence and child maltreatment.

\section{Gap in Literature}




\section{FATHERING INTERVENTIONS}

While the literature regarding father -focused batterer intervention programs has developed throughout the last 20 years, the discourse still lacks information regarding how effective the programs that have been implemented are and how specific aspects of these programs can result in different outcomes for them. This paper seeks to explore the different characteristics of two father focused batterer intervention programs: the Caring Dads program and the Addressing Fatherhood program. It will compare and contrast the structures, objectives, teaching strategies, and teaching topics of the two program's curriculums. This paper will seek to answer the question: How are fathering interventions are incorporated in batterer intervention programs and how these methods could possibly affect the outcomes and efficacy of the programs?

\section{Methods}

This paper seeks to answer the question: how fathering skills and interventions have been incorporated into the batterer intervention programs that are in use today? In an effort to answer this question, a content analysis was conducted on two father focused batterer intervention program curriculums: Caring Dads: Helping Fathers Value their Children (2nd edition) and Addressing Fatherhood with Men Who Batter: A Curriculum for Working with Abusive Men as Fathers in a Batterers Intervention Program (2nd edition). These texts were chosen to be the subjects of the content analysis because they are curriculums that are based on past BIP theories and that have actually been implemented either as their own programs or as an addition to existing BIPs.

The content analysis that was conducted focused on comparing and contrasting the different aspects of each program manual (White \& Marsh 2006). The first round of coding focused on the different aspects of how the fathering interventions are integrated into the programs and how the programs are designed using constant comparison and contrast. The texts were coded according to the structure, objectives, visuals used as teaching aids, examples used, teaching strategies, specifics around parenting and abuse, and how the child and the care of the child was incorporated into the teaching strategies. These codes were chosen because they constitute the characteristics of the curriculums that 


\section{FATHERING INTERVENTIONS}

could have an effect on the way that fathering interventions are integrated into the programs. A second round of coding was conducted to collapse the codes that had been identified in the first round and identify themes in the data. This paper explores these themes by examining how each of the curriculums/texts present each of the themes and comparing and contrasting them to each other.

\section{Data}

The first curriculum that will be examined in this paper is the 2nd edition of the Caring Dads: Helping Fathers Value their Children program manual by Katreena Scott, Claire Crooks, Tim Kelly, and Karen Francis. This program is a 17 week stand-alone father focused batterer intervention program that focuses on achieving the four primary goals of the program: to build trust between the men and the program facilitators in order to influence the men to look at the fathering actions they have taken, to teach the men how to apply child-centered fathering, to have the men take responsibility for their parent centered fathering and acknowledge how they can change it, and to have the men rebuild trust with their children and prepare for their relationships with their children in the future. This program seeks out participants that currently have some level of contact with their children but have not been committed for any child-related crimes that could mean that the child would be in more danger due to the contact with the father. This program's design was made to incorporate three core principles: the 17 two-hour sessions for a group of up to twelve men to facilitate a group intervention for the fathers in the program, the systematic outreach to the mothers to ensure that they are safe throughout the course of the program, and the coordinated case management between the child's case manager and the facilitators of the program to share information regarding the father's progress and what the child is experiencing at home.

The authors of Caring Dads have written their curriculum based on previous literature that had established that there was a need for batterer intervention programs focused on fathers and the father's treatment of their children as well as the father's treatment of the mother. Since Caring Dads was first implemented successfully, the authors of the program have conducted their own series of research to evaluate the program (Scott \& Crooks 2007) and determine the efficacy of it (Scott \& Lishak 2012). The evaluation of the program found from a small sample size of 23 men before and after they completed the 


\section{FATHERING INTERVENTIONS}

Caring Dads program, there was a significant decrease in the father's overall stress level; the father's level of hostility, denigration, and rejection of their child; and the father's level of angry arousal to child and family situations (Scott \& Crooks 2007). An examination of the efficacy of Caring Dads did find that the program had a statistically significant effect on changing the father's over-reactivity to children's behavior and their respect for the relationship they have with their child's mother (Scott \& Lishak 2012). While there is existing evaluation literature on the Caring Dads program it must be noted all of these evaluations were conducted by authors of the program rather than an unbiased researcher. The authors of this program have incorporated the information found through the evaluations and recommendations of program facilitators and participants into updating the 2nd edition text of Caring Dads. They explain how they incorporate new elements into the new edition (the edition examined in this paper) such as emphasizing communication with the other service providers that are connected to the family and suggesting child-centered fathering approaches before calling the men out on using certain parentcentered parenting techniques.

The second text examined in this paper is Addressing Fatherhood with Men Who Batter: A Curriculum for Working with Abusive Men as Fathers in a Batterers Intervention Program (BIP). This is a program that is offered as an addition to a standard batterer intervention program or as a stand-alone fathering program. It is offered to men that have contact with their children or so not contact with their children. The program curriculum consists of four themes focused on examining men's childhood experiences with their fathers, portraying the impact of battering on their children and their mothers, becoming a more child-centered father, and examining how men can be non-abusive and more supportive of their children's mother and of the mother-child relationship. These themes are supported through a variety of exercises that use role-playing, examples, distribution of advice, and the use of a fatherhood log after a majority of the exercises.

The Addressing Fatherhood program, while on its second edition, has not had any evaluation literature published to establish how effective the program can be. One of the reasons for this is that the program does not require program fidelity. This makes it difficult to evaluate because it is nearly 
FATHERING INTERVENTIONS

impossible to set a control group to compare against a group that follows the program to the standards outlined in the curriculum provided. The fact that the program does not require the facilitators to follow the outline provided in the curriculum, gives rise to the question of whether or not the Addressing Fatherhood program manual qualifies as a curriculum or not. It could be argued the text guiding the Addressing Fatherhood program does not qualify as a curriculum because the structural components of the program allows the facilitators to pick and choose aspects of the program, pick in what order to introduce the themes and the exercises, and decide what men to include in the program.

\section{Results}

\section{Theme 1: Curriculum Focus}

Both the Caring Dads and Addressing Fatherhood programs are based on batterer intervention programs that seek to make the men's relationships with the mothers of their children and the children better. Although these programs have the same universal objectives, they are based on slightly different theories to explain violence and they address the men's relationships with the mothers of their children and their own children in different ways. The Caring Dads program puts their primary focus on building and strengthening the men's relationships with their children. While they do acknowledge to have a healthy relationship with their children the men also must have a nonviolent and respectful relationship with their children's mother, the Caring Dads program spends a limited amount of time into putting class time toward this goal. The Caring Dads program devotes two of their sessions to focusing on the relationship with the mother. These sessions suggest men's mistreatment of mothers can have a negative effect on the children and give the men an opportunity to come up with alternative ways to treat the mothers in a more respectful and peaceful way.

On the other hand, Addressing Fatherhood takes a different approach to the focus of their program. The Addressing Fatherhood program devotes a significant portion of the curriculum to addressing men's use of violence against the women in their lives. While Addressing Fatherhood is father-focused and does provide fathering skills and information about child's development stages, this program puts an emphasis on the fact that abuse of mothers can have a profound and negative effect on 


\section{FATHERING INTERVENTIONS}

their children. Out of the four themes that the Addressing Fatherhood program is built around, an entire theme with six exercises is devoted to addressing violence against women using the same types of exercises also used to address violence against children. These exercises address violence against the mother through the use of stories from interviews that were conducted with a victim of mother focused abuse, sharing ideas about how to be a more respectful and supportive parenting partner, utilizing the teaching strategy of role-play to examine how this type of violence can affect the mother-child relationship, and empathy building exercises focused on the batterers relationship with the mother.

\section{Theme 1: Conclusion}

The focus of each of program shapes what type of batterers could benefit from the program.

Because Caring Dads structures their program to put an extra focus on the children, it would make sense that this program could be more effective in reducing future violence for men who have children who have a history of child maltreatment than men who have more of a past of intimate partner violence. Following the same theme, because Addressing Fatherhood puts an increased emphasis on addressing violence against mothers and women, it would be reasonable to say that this program would be more applicable toward reducing violence toward mothers. This conclusion can be further illustrated by the participant criteria outlined in each program. For example, Caring Dads' requirements for participants ensures that participants are fathers and have some level of contact with their children while the Addressing Fatherhood requires that their participants must have a past of battering but does not specify that this violence had to be projected at children or even that the participant have any children that they are a father figure to.

\section{Theme 2: Program Fidelity}

The structural components of both curriculums examined in this paper influence how each program can be evaluated and even how effective each program could be in decreasing the use of child maltreatment and intimate partner violence. Structural elements such as the way the curriculum directs their program to be implemented influence the way that facilitators have to implement the program and how effective these programs are as a result. 


\section{FATHERING INTERVENTIONS}

Program implementation. Each of the programs examined provide their own instructions on how they want their programs implemented. These specifications can range from general guidelines that allow facilitators choose what will work best for their participants, to strict guidelines that detail how to respond to the majority of situations and people. The authors of Caring Dads specify that the program should be implemented through the step by step guidelines provided in the curriculum. One example of this is when the program recommends that each program should have two facilitators: one male and one female both with experience working in batterer intervention programs. Facilitators must also follow the layout and the exercises in the program, the recommendations on choosing participants for the programs, and the 17 session calendar provided for the curriculum. The authors also add a generous amount of "facilitator's notes" to help the facilitators deal with common arguments that men may make against the class material, focus class material on the type of battering that each group might focus on, and provide tips on how to encourage the men to be honest and thorough when describing their own situations. One textual example of this is in Session 3 when the authors provide three different options to use as exercises, and clearly explains which type of group each exercise would be most applicable for.

The implementation instructions of Addressing Fatherhood are more general and flexible. Examples of these relaxed specifications are that the participants do not necessarily have to be fathers to be part of a group, and facilitators can pick and choose from the themes provided to implement them in the order that they believe will be most effective. This program also does not specify the form in which the program should be taught. According to the Addressing Fatherhood text, the curriculum can be incorporated into an existing BIP, taught on its own, or taught as extra classes in addition to the BIP (Scaia et al. 2010). The instructions that are provided in the text ensure that the facilitators will be able to implement the themes and exercises of the program at their discretion to address the needs of the men in the current group. This can be effective because it allows facilitators to take into account the battering histories of the men in their group and the needs and motivation levels of the men at different stages in the group. 


\section{FATHERING INTERVENTIONS}

Curriculum layout. The way the curriculum is laid out influences the way that men can accept the information presented and retain the information and skills taught. Each program examined provides a curriculum layout based on different perspectives of how men will react ot the information and exercises provided. Caring Dads devotes the first three sessions of the program to creating a relationship and building rapport with the men in the group before digging into the men's current issues with the children and their mothers and challenging the men to change their actions. The program is structured this way to address the fact that most men are unwilling to immediately admit that they need parenting help and that their current parenting techniques should be changed (Scott et al. 2014 pg.16).

Addressing Fatherhood takes a different approach with the curriculum design. The themes in Addressing Fatherhood can be taught in any order that the facilitator feels is right for the group and there is no specific theme or exercise that seeks to build a relationship with the men. Although this program prefers that facilitators be able to move through the teaching exercises at the pace that the group needs, there are exercises in which the writers warn that there are exercises that could be hard to deliver if there is no established trust and relationship with the men. For example, when the authors discuss how to present the curriculum, they recommend making decisions based on the dynamics of the group. If the group seems like they will be receptive to the information than the program can be delivered in the way the facilitators choose, but if it seems that the men will not be open to talking about their relationships with their own fathers than it would be preferable to begin the program by focusing on the theme that discusses the actions necessary to become a better father (Scaia et al. $2010 \mathrm{pg} .28$ ).

\section{Theme 2: Conclusion}

Because the curriculums have different specifications about how each curriculum should be structured and how facilitators should implement their programs, each program will be better suited to different types of participants and have to be evaluated in different ways. Caring Dads stresses program fidelity and following the guidelines that are outlined in the text, so this program has been easily replicated in various cities throughout the UK and Canada. It also means that this program would be easier to evaluate in terms of efficacy because all of the programs that are implemented seek similar 


\section{FATHERING INTERVENTIONS}

participants, follow the same structure, and teach the same parenting information and skills. An evaluation or efficacy study for one Caring Dads program can be generalized to all of the programs that follow the Caring Dads curriculum.

The Addressing Fatherhood program would be far more difficult to evaluate because it is not guaranteed that any of the programs that follow the Addressing Fatherhood curriculum maintain the same elements. Different programs with different facilitators could have a wide range of participants, could stress the necessity of different information and skills, and integrate the teaching topics of Addressing Fatherhood into a BIP in different ways. They can also administer the four themes in the curriculum of the program in any order that would benefit the way the format that the program is being implemented (as an addition to a BIP, stand alone, etc.) and the dynamics and characteristics of the men in the group. Because the program does not stress program fidelity, there are many different ways that the program could be implemented that would skew efficacy results when studies are conducted. There is no guarantee that the findings of one study for one Addressing Fatherhood program could be generalized to other Addressing Fatherhood programs. This can result in expectations for the program that has more to do with the decisions of the program facilitators rather than the structure and content of the program itself.

\section{Theme 3: Teaching Strategies}

Both Addressing Fatherhood and Caring Dads use different teaching strategies to reinforce the ideals and the skills that they want the men to learn from the program. While both programs distribute knowledge pertaining to domestic violence and child maltreatment, they take different approaches when determining what type of information should be shared and emphasized. Through an examination of the texts, it was found that Caring Dads also emphasized extra teaching strategies such as an increased focus on group participation and encouragement of men's hope for their future relationships with the mother and their children.

Group participation. The Caring Dads program focuses on sharing the information in their sessions then asking the men in the program to relate it back to their current parenting difficulties in their present situation. The use of group participation allows men to get help with the problems that they are currently 


\section{FATHERING INTERVENTIONS}

experiencing from men that could be having the same difficulties in their own homes. It also gives men the opportunity to share the difficulties that they are having and come to the realization that there are problems that many others have experienced. The element of group participation can also come with negative result. Group participation does not ensure that men learn the parenting skills that are needed to be able to change as the situation and relationship with their children change because they pool ideas and encouragement from other participants of the group.

The Addressing Fatherhood program focuses on applying the information that has been taught in class to role play scenarios and providing examples on how to change behavior in common difficult situations the men might encounter. This allows men to learn how they should respond to the majority of dilemmas they might face as a parent while giving them a list of ideas that they could try and apply to their current difficulties. One of the negative aspects of not focusing class time on group problems is that the group does not address the problems that the men might have at that particular moment. This forces them to use the examples that are provided in class without knowing if they apply to the men's current problems. This teaching strategy also prevents the men in the group from knowing what troubles other participants might be having. While this can be good because it does not force any men into a position that would make them uncomfortable by sharing details of their personal life, it could result in some of the men's difficulties not being addressed.

Sharing knowledge. One of the Caring Dads and Addressing Fatherhood program's main teaching strategies is to share knowledge regarding the relationship between the IPV and child maltreatment, how children go through different development stages, and what qualifies as IPV and/or child maltreatment with the men in the group in order for them to understand what domestic violence is and how they can change it. While both of these programs relate the same type of information, they do it by stressing different types of information regarding domestic violence and its effects on children. Caring Dads focuses on sharing information related to the children's developmental stages and the way children will typically respond to different types of parenting behavior. For the example, in Session 4 the authors employ an exercise that assigns men in the group different developmental stages, and then they ask the 


\section{FATHERING INTERVENTIONS}

men to identify behaviors that their own children use that are related to their developmental stage. This exercise is designed to teach the men about the variety of child behaviors that are normal for children's developmental stages.

Addressing Fatherhood utilizes many of the same methods to share similar information. This program relays information about children's developmental stages and the way that children will respond to different parenting behaviors, but they do this while stressing information regarding the link between IPV and CM. Addressing Fatherhood puts a larger focus (than Caring Dads does) on how abusing a mother can negatively affect the child and affect the mother-child relationship by degrading the mother while the child is present. This program relates information to the participants of the group that violence toward the mother can influence the child to lose faith and respect for the mother while also affecting the way the women feel as mothers. For example, all of Theme 4 is focused on distributing the message that men need to respect and support children's mothers in a nonviolent way to support the mother-child relationship. The second exercise to support this theme prompts the men to role-play a scenario in which the mother gets berated by the male in the relationship in front of her children. The curriculum then offers an extensive list of actions men might do that can negatively affect the women and the children in their lives (Scaia et al. 2010 pg. 98-99).

Encouragement for hope of possible future change. A constant goal of the Caring Dads program is to encourage the men that making a change in their parenting and their relationships with the women and the children in their lives is an achievable goal. If the men in the group have no hope that things will get better then they have no motivation to make changes to their parenting behavior. Encouraging the men that all of them can potentially be good parents with good relationships with their children allows the men to move forward in the program without focusing on the frustration of having a hard time changing their ways. For example, there are many times in the text the authors encourage the facilitators to focus on hope for the future if there is no immediate answer to a problem a man presents in the session.

Addressing Fatherhood does not focus on encouraging the men to have hope for the future. While there is always encouragement that the men will be able to learn to respect the women and the children in 


\section{FATHERING INTERVENTIONS}

their lives, they do not directly focus on hope. They do employ the use of role-playing exercises in order to get a feel for the type of reactions that certain parenting actions will illicit. These practices show the men that implementing the skills learned in class will (hopefully) result in a positive interaction. While I would not classify the use of role-playing as a direct way to encourage men to have hope, it can produce the result by displaying what actions can elicit a good result. These exercises can create hope by projecting a positive image in relation to certain types of positive actions and interactions.

\section{Theme 3: Conclusion}

All of the subthemes examined in this paper influence the types of problems each of the programs are outfitted to try and solve. The difference in each program's use of group participation, their selection of knowledge to share, and their focus on encouragement to change influence the way the men in the programs can solve the problems they encounter while going to group. Many of the group participants for Caring Dads and Addressing Fatherhood have limited access to their children and strained relationships with the women and children in their lives (Scaia et al. 2010; Scott et. al 2013). This can make it difficult for the men to use the new parenting skills they have learned in group to try and build better relationships with their children and the mothers. Men can have a difficult time trying to get their children and the mothers to trust them or even agree to be in contact with them.

The difference in the ways Addressing Fatherhood and Caring Dads address group participation, the selection of knowledge to share, and the encouragement for hope in the future changes the way the groups can interpret and help with problems the men experience while trying to use the skills learned in class. Caring Dads creates a group that is flexible to the nature of the problems the men might be having by creating a large focus on group participation that encourages the men to share the problems they have encountered and allows the other men to contribute in finding a way to solve the problem. The group's constant focus on hope for future change also encourages the members to focus on the long run rather than what they are experiencing at the moment. Caring Dads creates an environment that allows the men to come to the group sessions with their problems to try and brainstorm to find a solution. This is further 


\section{FATHERING INTERVENTIONS}

exemplified by the program's use of check-ins and check-outs that focus on the men in group for every session.

Addressing Fatherhood takes a different approach to what the men should gain from the program through their decreased use of group participation and hope for the future and their heightened focus on sharing knowledge. This program is focused on distributing information and educating the men on abuse while also using exercises to make the men emphasize with women and children that have experienced abuse. This is demonstrated through the use of lists of examples that are used to support many of the exercises focused on distributing information about abuse and how to avoid it. Addressing Fatherhood takes less of a hands-on approach to the problems the men face while participating in the group than Caring Dads does, but they put more of a focus on outfitting the men with the tools necessary to find alternatives to abuse. This could be more appropriate for the target group of the program because the participant criteria is general enough that it includes a wide range of men that could include men who might not even be in contact with their children. Addressing Fatherhood is more focused on preparing men to be good fathers when their participants might need those skills.

\section{Theme 4: Teaching Topics}

Some of the primary teaching topics addressed in both programs are empathy building, teaching parenting skills, and focusing on men's own history of violence. While each of these are core teaching topics of each program, the way they are integrated into each of the curriculums influence the way that the men who are part of the program accept and start using the skills taught in the class.

Building empathy. One of the popular teaching topics used in each program is the use of various activities to encourage the men to emphasize with the women and children that would be the victims of domestic violence. Both curriculums attempt to build empathy for both the children and the mothers. They also both share the belief that denial and minimization can be dangerous to the mothers and children that are the victims of domestic violence and blocks the men's ability to build empathy for the women and children. Both programs address the dangers of denial and minimization of the men's violence. Caring Dads does this by devoting an entire session (Session 14) to explaining these terms so the men can 


\section{FATHERING INTERVENTIONS}

distinguish between them while Addressing Fatherhood challenges denial and minimization by providing an exercise (Theme 3: Ex 8) that encourages men to call each other out for their abusive actions. Another element present in both programs that can have the effect of creating empathy for the mother and the children who have been victims of domestic violence, is the encouragement to explore the men's personal histories and relationships with their own fathers. This is a teaching topic employed in both programs to different extents. For example, Addressing Fatherhood devotes one of their themes to exploring what type of effect their fathers had on them and what types of behaviors they learned and have copied from their fathers. While both programs do not specify that a specific goal of these exercises is to build empathy, revisiting the experiences the men had as children is effective in prompting the men to empathize with the women and children in their lives.

While both of these programs seek to encourage empathy for women and children who are victims of abusive acts, they try to achieve this goal using different methods. One of the ways Addressing Fatherhood does this is by having the men role play and put themselves into their children and their mother's shoes. They take turns acting out a scene in which an abusive act is occurring and try to act as a mother or a child would act in that situation. This exercise is designed to encourage the men to look at what women and children have experienced from their behavior and imagine how those actions could have a negative effect on the people they are being directed towards. They also use visuals to encourage empathy for the children such as drawings and letters by children that portray how the children perceive violent behavior that is directed toward the mother or the child and videos of children's perspective of violence. For example, in Theme 4-Exercise 3, a key component of the exercise is a video filmed from a child's perspective as the child walks through a house that was destroyed by a violent fight and tries to find her mother. The video employs depressing music and sounds of a sobbing and frightened child to encourage the men who are watching it to emphasize with the child.

Caring Dads tries to build empathy by explaining how violence can negatively affect their children. This is done in a way that distributes information about the struggles children undergo through each stage of their development and how experiencing domestic violence can change the way that 


\section{FATHERING INTERVENTIONS}

children view people, relationships, and their own actions throughout life. They also prompt the men in their programs to try and better understand their children the next time they experience conflict with their child. By prompting the men to apply the information they have learned in class to their own time with their children, the program encourages men to empathize with the situation their child is experiencing and apply the parenting skills they have learned in class. Because of this, all of the exercises that ask the men to identify the parenting behaviors that disregard the child are utilized to encourage the men to empathize with their children.

Parenting skills. One of the primary teaching topics Addressing Fatherhood and Caring Dads share in common is their focus on teaching the participants child-centered parenting. Because teaching the men better ways to parent and relate to their children is one of the primary goals to both of these programs, they both spend a great deal of class time on teaching parenting skills. Both curriculums teach that there are different parenting skills for the different child development stages. They both stress how children will respond to different types of discipline and parenting practices at different ages, and how the fathers should be prepared to respond to misbehavior. An example of this is both programs spend an exercise/session focusing on how discipline is different from punishment (CD Session 16, AF Exer 3:7). Addressing Fatherhood does this by having the men in the group classify different methods of parenting (spanking, yelling, etc.) as discipline and punishment, then delving into the types of parenting motivations that differentiate punishment from discipline. This program focuses on the fact that punishment is motivated by the desire for power and control over the child's actions. Caring Dads addresses this distinction by pointing out punishments are parent-centered actions and tries to encourage the men to pick discipline methods representative of child-centered practices.

Caring Dads teaches men these parenting skills by giving examples of good and bad parenting, asking the men to identify their own parent centered actions, and practicing the replacement of parentcentered actions with child centered actions. The way that Caring Dads demonstrates the difference between types of parenting behaviors is the Parent Centered vs. Child Centered Continuum. This is the teaching tool the Caring Dads facilitators utilize to demonstrate what types of parenting behavior will 


\section{FATHERING INTERVENTIONS}

benefit the children. The Parent Centered vs. Child Centered Continuum is referenced in many of the sessions to be used as a tool to differentiate between the types of parenting decisions the men want to be making and how they naturally want to act. This program also has the men set a goal to change a parenting behavior as homework for a couple of their sessions. They emphasize that the men should be consistent with their children. They should be reliable, show up for visits when they are expected to meet with their child, and be consistent about doing what is promised to the child.

Addressing Fatherhood takes a different approach to teaching parenting skills. Addressing Fatherhood defines what child centered parenting is and provides a list of examples of child centered parenting techniques the men could use. This program uses the teaching strategy of having the men look back at the parenting techniques their fathers used and deciding what is appropriate to leave behind or carry forward. One of the exercises employed asks the men to look at a handout titled "The Intergenerational Cycle of Battering" and identify beliefs the men formed when they were children that were based from what their own fathers had taught and modelled for them. The men are then asked to decide which of these beliefs the men want to "Carry Forward" by sharing and modelling the beliefs for their own children. The goal of this exercise is to make the men understand that they are a role model for their children, so their own behavior can be a parenting skill in itself.

Men's personal histories with violence. Research has found that there is a link between the number of men who batter and the men who were battered as children (Zanoni 2014). Both curriculums address this in their groups by exploring what the men in the group experienced from their own fathers and how those actions affected them. Caring Dads starts the curriculum by examining the experiences the men had with their own fathers (Session 2). This session includes an exercise that encourages men share with the group the members of their families and their current living situations and an exercise that has the men explore the way they were parented and create new suggestions about how they should have been parented. Starting the program in this way allows the men to explore what type of parenting actions they liked when they were children and what type of parenting behavior they did not like. It starts off the group by 


\section{FATHERING INTERVENTIONS}

attempting to have the men emphasize with what their own children might experience because they have experienced similar actions before.

Addressing Fatherhood addresses this by devoting one of their four themes to examining the men's histories with their fathers and what these actions had taught them that they still carry today. The theme that is presented in the curriculum focuses on how the parenting the men experienced as children influenced the way they parent with their own children. An example of one of these exercises is Theme 1: Exercise 8 Was I abused as a child? This exercise asks the men to create a pie chart of the types of abuse that they experienced from their own father when they were children (Scaia et al. 2010 pg. 51). Addressing Fatherhood emphasizes that exploring the way the men were treated as children can force the men to realize some of the actions they take are abuse and helps them create empathy for their children by bringing them back to when they were treated that way as children. The authors use this as a foundation for the entirety of the curriculum. They prompt the men to apply much of the information presented in class to the men's personal experiences with their own fathers. This allows the men to see if what is being said in class is accurate from their own experience and validates the new information.

\section{Theme 4: Conclusion}

The teaching topics are the foundational goals of each of the program's structures. The way they are implemented and emphasized can directly influence what type of skills and information the men can get out of the group, the receptivity the men will have to the new ideas being introduced, and how the men view the women and children in their lives. Because every person responds to the various teaching topics in different ways, the different ways each teaching topic is presented in the two texts will have a range of effects on the men that experience them. An example of this is the teaching topic of building empathy. Some people might begin to empathize with victims of abuse when they hear the first-hand accounts from the children who experienced these events, and some might learn better when they are told how their children experience domestic violence. The different ways the topics are addressed influence what skills the men will build throughout the course of the program. 


\section{FATHERING INTERVENTIONS}

The way Addressing Fatherhood implements the teaching topics of empathy building, new parenting skills, and men's history of violence targets a general population of batterers. Instead of crafting their exercises around the men's current lives and circumstances, this program takes a general approach and tries to implement the teaching topics in ways that any of the men can relate to. For example, the visuals used can affect anybody in the group regardless of whether they have children of their own or if they have a current relationship with a woman in their lives. This program also makes a point of providing lists of examples that support the point the exercises are trying to make. For example, in Theme 1: Exercise 3 the authors provide a list of 53 examples of commonly held beliefs by men who batter. The exercises in Addressing Fatherhood are extensive because they are designed to be applicable to a large, diverse audience. The way the teaching topics are implemented in Addressing Fatherhood result in participants learning to empathize with all women and children that are victims of abuse and how to utilize the new parenting skills encouraged and provided in the text. The program sets its participants up to respond to conflict they might encounter in the future in a healthy and child-centered way.

Addressing Fatherhood focuses on all of the teaching topics discussed above by providing the curriculum for them and allowing the facilitators to decide what they will administer. Because there are no requirements as to how the themes in the Addressing Fatherhood text have to be taught, the teaching topics of parenting skills and men's childhood experiences with their fathers are stand-alone topics that are taught through an entire theme or a variety of exercises while the topic of building empathy is a goal throughout the entirety of the program. The way each of these topics are addressed make the program more flexible to what the men might need when the program is actually administered. The structure of the program allows facilitators to pick and choose teaching topics they wish to teach. For example, if men are not comfortable with sharing or exploring their childhood experiences with their fathers than that particular theme does not have to be emphasized or if most of the men in the group do have contact with their children the parenting skills theme can be emphasized. The way these topics are implemented can influence how receptive men are of the new information, though, depending on how each teaching topic is broached in the group. The variety of ways the Addressing Fatherhood text can implement the teaching 


\section{FATHERING INTERVENTIONS}

topics can lead to a variety of endings that can range from men being incredibly successful in group to men feeling like the program is asking for too much and dropping out.

The approach Caring Dads takes to implementing the teaching topics in their program is more specific to the men in the group. The way their teaching topics are implemented encourage and support the men in trying to find solutions to the conflicts they are experiencing with their children and the mothers. For example, when teaching parenting skills, Caring Dads defines parent-centered and childcentered parenting and then spends class time brainstorming with the group about what types of actions classify as which. This encourages the men to develop the skills required to be able to choose what type of action is an appropriate response to conflict. The way these teaching topics are implemented can teach the men how to respond to a variety of conflicts after analyzing the situation and deciding what the most appropriate course of action would be. This program prepares the men to be able to navigate conflicts with their children and the women in their lives on their own by prompting them to practice coming up with solutions to the conflicts that are identified in class.

Since Caring Dads implements the teaching topics in a very strict process that focuses on trying to develop a trusting relationship with the men in the group first before trying to teach the men anything or delving into the men's history with their fathers, there is less of a chance that the way the teaching topics are implemented will influence how receptive men are to what is being taught in the program. Caring Dads is designed to focus on parenting skills, empathy building, and men's relationships with their father to the same extent in every Caring Dads group. Each of these teaching topics are addressed in sessions throughout the course of the program to the extent the authors thought best. While this makes the program less flexible to what the men need from the group, it does provide a stable curriculum that focuses on trying to discourage men from dropping out or from not being receptive to the new information presented. All of the men in a Caring Dads program should learn the same amount from each teaching topic regardless of if they were different groups are not. 


\section{FATHERING INTERVENTIONS}

\section{Discussion}

The data presented in the earlier pages came to four broad conclusions: 1.) That the focus of each curriculum influences the type of batterers the programs would be most effective for, 2.) fidelity to the program layout determines how accurate any efficacy and evaluation studies of the programs would be, 3.) the teaching strategies employed in each program define the types of conflicts each program is outfitted to try and solve, and 4.) the way the primary teaching topics are integrated into each program influences the types of batterers that can be most influenced by the program and the men's receptivity to the information and skills provided. The conclusions that were drawn after a careful analysis of the data show that each of the program's structures and the layout of their programs influence what types of batterers the programs would be most effective for. While there are many similarities in the types of exercises used and the teaching topics of each program, the teaching strategies used in each program and the way these exercises are implemented influence the effect the programs can have on batterers.

Both Addressing Fatherhood and Caring Dads have some of the same goals in mind for their programs: decrease men's use of violence and abusive methods toward their children and the mothers of their children, teach men healthy and safe parenting skills to manage conflict with children, and encourage men to understand their children and the mothers so they can attempt to have a healthy relationship with them while addressing them in different ways. The similarities in each program's goals lead them to be similar in exercises and themes because they are trying to achieve similar results, but the differences are what are meaningful to the conclusions drawn in this paper. The differences in the two programs definitely contribute to how accurate evaluations of the program would be if either of the programs were to be evaluated and how effective the programs would be for specific types of batterers in different types of family situations. While the similarities in the program objectives mean either program should be effective for any type of batterer, the differences in structure and teaching strategies and implementation of teaching topics mean each program has a target audience it would be most useful for.

There is no evidence through efficacy or evaluation literature to support these conclusions because there have been very few evaluations done on Caring Dads and no evaluations conducted on 


\section{FATHERING INTERVENTIONS}

Addressing Fatherhood, but the literature does identify that the Caring Dads program is effective in reducing different behaviors that lead to violence such as the fathers' level of hostility, denigration, and rejection of the child and men's level of angry arousal to child and family situations (Scott \& Crooks 2007). Because of the small number of efficacy studies that have been conducted on these programs, there have been no conclusions drawn as to what type of battering these programs reduce. It would be useful to investigate the recidivism rates of the men referred to either program in an effort to determine if the programs are effective in reducing future domestic violence or child maltreatment incidents.

\section{Limitations}

The analysis conducted on these two programs is limited because we have no practical experience administering batterer intervention programs or observing them being conducted. There was also no discussion or inclusion of program participants, authors who created the programs, or other facilitators. This limits the conclusions that have been drawn in this paper because the research does not include the motivations or opinions of the people who actually implement and participate in these father focused batterer intervention programs.

\section{Recommendations}

A direction for future research would be to conduct efficacy studies of both Addressing Fatherhood and Caring Dads because it would be useful in determining how effective these programs are in reducing recidivism. It would be useful to develop a standard version of the Addressing Fatherhood program to evaluate the program's effectiveness, although, it would be difficult to generalize these findings to the Addressing Fatherhood program because there are so many ways that the program can be implemented. Further investigation into the methods employed in other father-focused batterer intervention programs would also be helpful in identifying the exercises and themes in the programs that make the greatest impact on the men in the group. Conducting further research to determine in what way each of the programs are effective and for what type of batterers they are most effective for could shape the direction that father focused batterer intervention programs take in the future. 
FATHERING INTERVENTIONS

\section{References}

Babcock, J.C., Green, C.E., \& Robie, C. (2004). Does batterers' treatment work? A meta-analytic review of domestic violence treatment. Clinical Psychology Review, 23(8), 1023-1053 doi:

10.1016/j.cpr.2002.07.001

Bautista, Bohall, \& Musson (2016). Intimate Partner Violence and the Duluth Model: An Examination of the Model and Recommendations for Future Research and Practice. Journal of Family Violence. 31:1029-1033 doi: 10.1007/s10896-016-9888-x

Oregon Department of Health Services. (2016). What is Domestic Violence? Retrieved from https://www.oregon.gov/DHS/ABUSE/DOMESTIC/Pages/definition.aspx

Edleson, J. L. (1999). The Overlap between child maltreatment and woman battering. Violence Against Women, 5(2), 134-154. http://doi.org/10.1177/107780129952003

Faulkner, K., Stoltenberg, C. D., Cogen, R., Nolder, M., \& Shooter, E. (1992). Cognitive-Behavioral Group Treatment for Male Spouse Abusers. Journal of Family Violence, 7(1), 37-55.

Herman, K., Rotunda, R., Williamson, G., \& Vodanovich, S. (2014). Outcomes From a Duluth Model Batterer Intervention Program at Completion and Long Term Follow-Up. Journal of Offender Rehabilitation, 53(1), 1-18. doi:10.1080/10509674.2013.861316

Kimball, E. (2015) Edleson Revisited: Reviewing Children's Witnessing of Domestic Violence 15 Years Later. Journal of Family Violence. doi: 10.1007/s10896-015-9786-7

Labarre, M., Bourassa, C., Holden, G. W., Turcotte, P., \& Letourneau, N. (2016). Intervening with fathers in the context of intimate partner violence: An analysis of ten programs and suggestions for a research agenda. Journal of Child Custody, 13(1), 1-29 doi: 10.1080/15379418.2016.1127793

Langhinrichsen-Rohling, J., Mccullars, A., \& Misra, T. (2012). 10 Motivations for Men and Womens Intimate Partner Violence Perpetration: A Comprehensive Review. Partner Abuse, 3(4), 1-33. doi:10.1891/1946-6560.3.4.e10 


\section{FATHERING INTERVENTIONS}

McConnell, N., \& Taylor, J. (2014). Evaluating Programmes for Violent Fathers: Challenges and Ethical Review. Child Abuse Review, 25, 183-191 doi: 10.1002/car.2342

McHugh, M., \& Frieze, I. (2006). Intimate Partner Violence. Annals of the New York Academy of Sciences. doi:https://doi.org/10.1196/annals.1385.011

Palmstierna, T., Haugan, G., Jarwson, S., Rasmussen, K., \& Nottestad, J. A. (2012). Cognitive-behavior group therapy for men voluntary seeking help for intimate partner violence. Informa Healthcare, 66, 360-365 doi: 10.3109/08039488.2012.665080

Pennell, Joan, Rikard, R.V., Sanders-Rice, Tia. (2013). Family Violence: Fathers assessing and managing their risk to children and women. Children and Youth Services Review, 47, 36-45 doi: 10.1016/j.childyouth.2013.11.004

Reaves, B. A. (2017). Police Response to Domestic Violence, 2006-2015 (Rep.). US Department of Justice. Retrieved from https://www.bjs.gov/content/pub/pdf/prdv0615.pdf

Rothman, Mandel, Silverman. (2007). Abuser's Perceptions of the Effect of Their Intimate Partner Violence on Children. Violence Against Women. 13 (11). doi: 10.1177/1077801207308260

Saunders, Daniel G. (2008). Group interventions for men who batter: A summary of program descriptions and research. Violence and Victims, 23(2), 156-172 doi:10.1891/0886-6708.23.2.156

Scott, K. L. (2004). Predictors of Change Among Male Batterers: Application of Theories and Review of Empirical Findings. Trauma, Violence, \& Abuse, 5(3), 260-284 doi: 10.1177/1524838003264339

Scott, K. L., \& Crooks, C. V. (2006). Intervention for abusive fathers: Promising practices in court and community responses. Juvenile and Family Court Journal, 57(3), 29-44. doi: 10.1111/j.1755-6988.2006.tb00126.x

Scott, K. L., Crooks, C. V. (2007). Preliminary Evaluation of an Intervention Program for Maltreating Fathers. Brief Treatment and Crisis Intervention, 7(3), 224-238 doi: 10.1093/brief-treatment/mhm007 


\section{FATHERING INTERVENTIONS}

Scott, K. L., Lishak. (2012). Intervention for maltreating fathers: Statistically and Clinically significant change. Child Abuse \& Neglect. 36(9), 680-684 doi:10.1016/j.chiabu.2012.06.003

White, M. D., Marsh, E. E. (2006). Content Analysis: A Flexible Methodology. Library Trends, 55(1), 22-45 doi: https://doi.org/10.1353/lib.2006.0053

Wissow, L. S. (1995). Child Abuse and Neglect. The New England Journal of Medicine, 332(21), 14251431 doi: 10.1056/NEJM199505253322107

Wolfe, D. A., Crooks, C. V., Lee, V., McIntyre-Smith, A., \& Jaffe, P. G. (2003). The effects of children's exposure to domestic violence: A meta-analysis and critique. Clinical Child and Family Psychology Review, 6(3), 171-187

Zanoni, Lee. (2014). Child protection fathers' experiences of childhood, intimate partner violence, and parenting. Children and Youth Services Review, 46, 91-102 doi:

10.1016/j.childyouth.2014.08.009

\section{Texts Examined:}

Scaia, M., Connelly, L., \& Downing, J. (2010). Addressing Fatherhood with Men Who Batter: A Curriculum for Working with Abusive Men as Fathers in a Batterers Intervention Program (BIP).

Scott, K., Kelly, T., Crooks, C., \& Francis, K. (2013). Caring Dads: Helping Fathers Value their Children. 